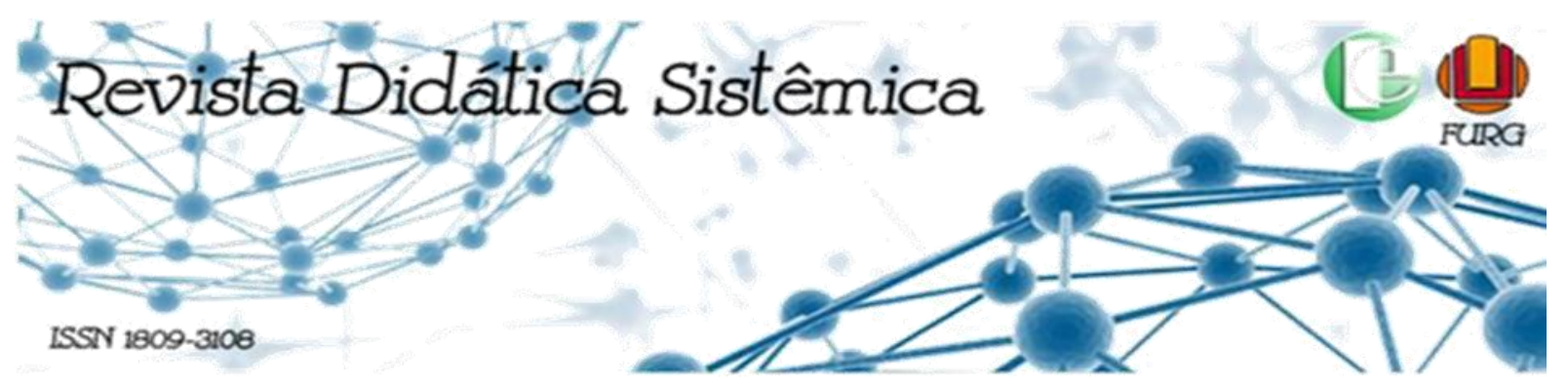

\title{
SPORT CLUB INTERNACIONAL: SOBRE O FUTEBOL DE MULHERES NO CLUBE DO POVO
}

\author{
Ana Laura Eckhardt de Lima* \\ Luiz Felipe Alcantara Hecktheuer ${ }^{* *}$
}

\begin{abstract}
RESUMO
Este artigo toma por tema central o futebol de mulheres do Sport Club Internacional. Tal delimitação compôs parte de uma pesquisa que visou diagnosticar a relação entre as mulheres e o futebol, no Rio Grande do Sul. Através de conversas com integrantes da comissão técnica da equipe de mulheres do Internacional e da busca por acontecimentos implicados com o tema, acompanhamos e descrevemos a reativação do departamento de futebol de mulheres desse clube, no ano de 2018. Concluímos que o cenário que tornou possível tal reativação foi composto por uma rede de acontecimentos nos quais as mulheres protagonizam, em diferentes oportunidades, disputas por espaços que não nos permitem acatar qualquer explicação unicausal ou na qual as próprias mulheres não assumam protagonismo.
\end{abstract}

Palavras-chave: Mulheres. Futebol. Sport Club Internacional.

\section{SPORT CLUB INTERNACIONAL: ON THE FOOTBALL OF WOMEN IN THE CLUB OF THE PEOPLE}

\begin{abstract}
This article focuses on the women's soccer of the Sport Club Internacional. This delimitation was part of a research that aimed to diagnose the relationship between women and football in Rio Grande do Sul, south of Brazil. Through talks with members of the technical team of the women's team from Internacional and the search for events related to the theme, we follow and describe the reactivation of the women's football department of that club in the year 2018. We conclude that the scenario that made such reactivation possible was composed of a network of events in which women lead, in different opportunities, disputes for spaces that do not allow us to accept any single explanation or in which women themselves do not assume a leading role.
\end{abstract}

Keywords: Women. Soccer. Sport Club Internacional.

\section{SPORT CLUB INTERNACIONAL: SOBRE EL FÚLTBOL DE MUJERES EN EL CLUB DEL PUEBLO}

\section{RESUMEN}

Este artículo tiene por tema central el fútbol de mujeres del Sport Club Internacional. Esta delimitación compuso parte de una investigación que visó diagnosticar la relación entre mujeres

\footnotetext{
${ }_{* *}^{*}$ Mestranda do PPG em Educação da Universidade Federal do Rio Grande - FURG

** Professor do Instituto de Educação da Universidade Federal do Rio Grande - FURG. Doutorado em Educação em Ciências pela Universidade Federal do Rio Grande - FURG
} 
y el fútbol en Rio Grande do Sul, sur de Brasil. A través de conversaciones con integrantes de la comisión técnica del equipo de mujeres del Internacional y de la búsqueda de acontecimientos implicados con el tema, acompañamos y describimos la reactivación del departamento de fútbol de mujeres de ese club en el año 2018. Concluimos que el escenario que hizo posible tal reactivación estaba compuesto por una red de eventos en los que las mujeres lideran, en diferentes oportunidades, disputas por espacios que no nos permiten aceptar una explicación única o en las que las mujeres mismas no asumen un papel de liderazgo.

Palabras clave: Mujeres. Fútbol. Sport Club Internacional.

\section{INTRODUÇÃO}

Este artigo apresenta os resultados de uma pesquisa, cujo tema central é o futebol de mulheres do Sport Club Internacional. Entendemos que a relação das mulheres com o futebol, dentro do clube, vem sendo construída há muitos anos, ao passo que algumas barreiras têm contribuído para que essa história seja marcada por descontinuidades, principalmente quando nos referimos ao futebol jogado dentro das quatro linhas. Isso porque, já nas décadas de 1980 e 1990, o Internacional possuía uma equipe bastante vitoriosa, revelando, inclusive, atletas para a seleção brasileira da época. Todavia, nos anos seguintes, uma lacuna se estabeleceu, adormecendo a modalidade que ressurgiria somente anos mais tarde.

Em meio a essas lacunas e continuidades, ao longo de sua história, o Internacional sempre valorizou a presença das mulheres, seja na arquibancada, no âmbito do conselho deliberativo ou nos gramados. No ano de 1918, Maria Von Ockel $^{1}$ se tornou a primeira mulher sócia de um clube de futebol no Brasil. Através das arquibancadas, Maria nos dá o primeiro registro da história das mulheres no futebol dentro do clube. Essa história se estendeu para o conselho deliberativo, o qual, anos mais tarde, contou com a presença da primeira mulher conselheira de um clube de futebol, a Jessy Bellomo Mancuso ${ }^{2}$.

No ano de 1940, o Internacional já contava com um departamento de futebol de mulheres, na época chefiado por Alayde Fagundes ${ }^{3}$, que também foi responsável por oficializar a primeira torcida colorada. Atualmente, conta com o maior número de mulheres

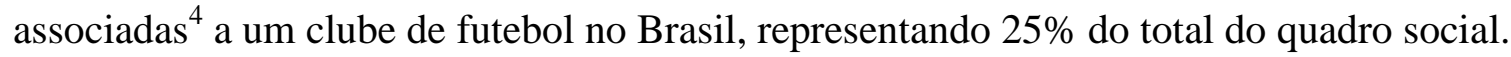

\footnotetext{
1Disponível em: <https://www.esporteinterativo.com.br/posts/24585-primeira-associacao-feminina-a-umtime-de-futebol-no-brasil-completa-100-anos>. Acesso em: 15 de outubro de 2018.

2 Disponível em: <http://memoriadointer.blogspot.com/2017/03/lugar-de-mulher.html〉. Acesso em: 15 de outubro de 2018.

3 Disponível em: <https://www.esporteinterativo.com.br/posts/24585-primeira-associacao-feminina-a-umtime-de-futebol-no-brasil-completa-100-anos>. Acesso em: 15 de outubro de 2018.

4 Disponível em: <https://radaresportivoufsm.wordpress.com/2017/03/12/a-estruturacao-do-futebol-femininono-inter-um-projeto-ambicioso/>. Acesso em: 15 de outubro de 2018.
} 
Nesse sentido, este artigo é um recorte do Trabalho de Conclusão de Curso ${ }^{5}$, produzido no ano de 2018, e tem como objetivo apresentar os resultados de uma pesquisa que toma a relação entre mulheres e futebol enquanto problemática, tendo seu escopo delimitado no futebol de mulheres do Sport Club Internacional. Para tanto, acompanhamos a reativação do departamento de futebol "feminino"6 do clube e descrevemos alguns acontecimentos com os quais nos deparamos, em que a relação entre mulheres e futebol mostrou-se evidente ao longo dessa história.

\section{DECISÕES DE MÉTODO}

Para dar consequência ao objetivo posto ao artigo, descreveremos as duas principais decisões de método que tomamos. Tais decisões são relativas aos procedimentos operacionais que tornaram possível: em primeiro lugar, o acompanhamento da retomada do futebol de mulheres no Internacional, partindo da reativação do seu departamento de futebol e para o qual optamos pela realização de conversas com algumas pessoas envolvidas no projeto; e em segundo, a descrição de alguns acontecimentos em que a relação entre mulheres e futebol mostrou-se evidente, e com os quais nos deparamos, ao buscar pela história das mulheres no clube colorado ${ }^{7}$. Tal busca se deu em sites, blogs, artigos acadêmicos e livros.

Desse modo, a decisão pela realização de conversas esteve relacionada ao desejo de estabelecer um diálogo: 1) sem preocupação com a estrutura; 2) sem que houvesse ritual de início, meio e fim; e, 3) sem uma noção de segurança (GONÇALVES, 2018). Buscávamos, assim, conversas ocasionais, embora houvesse clareza dos objetivos que nos levavam a realizar tais conversas. Nos amparamos nas palavras de Gonçalves (2018, p. 23), para a qual “a conversa é ordinária, ocorre por ocasião". Para Certeau (2003):

[...] as retóricas da conversa ordinária são práticas transformadoras "de situações de palavra", de produções verbais onde o entrelaçamento das posições locutoras instaura um tecido oral sem proprietários individuais, as criações de uma comunicação

\footnotetext{
5 Apresentado e aprovado no curso de Educação Física Licenciatura da Universidade Federal do Rio Grande no ano de 2018, sob o título "Futebol e mulheres: o acontecimento CONMEBOL e a reativação do departamento de futebol feminino do Sport Club Internacional".

6 Utilizamos a palavra feminino entre aspas, pois entendemos que não há um futebol feminino, enquanto características de feminilidade, mas sim um futebol praticado por mulheres. Contudo, em alguns casos recorremos a palavra "feminino" por uma questão linguística, visto que a palavra "mulheres" é muito utilizada nesse artigo.

7 Colorado é uma expressão usada para se referir ao Sport Club Internacional e seu/sua torcedor/a (colorado/colorada).
} 
que não pertence a ninguém. A conversa é um efeito provisório e coletivo de competências na arte de manipular "lugares-comuns" e jogar com o inevitável dos acontecimentos para torná-los "habitáveis". (p. 50)

As conversas ocorreram de dois modos, guardadas as especificidades de cada ocasião e sem um padrão pré-estabelecido: a) presencial; e b) em vídeo via Facebook, de modo individual. Nos preocupamos em informar sobre a realização da pesquisa antes de cada conversa e, para tanto, todas as conversas foram gravadas em áudio, após a autorização dos/as participantes. Além disso, em respeito aos aspectos éticos da pesquisa, solicitamos a assinatura do Termo de Consentimento Livre e Esclarecido, principalmente para os casos de uso destes registros.

No que se refere ao encontro com acontecimentos que colocam a relação entre mulheres e futebol em evidência, nos dedicamos a uma busca em fontes heterogêneas, assumindo que não visamos à totalidade destas. No entanto, pouco foram os achados que tratam do futebol de mulheres no Internacional, evidenciando uma carência de pesquisas e, inclusive, de notícias referentes a trajetórias das mulheres no clube colorado. Neste ponto, consideramos importante salientar que uma das fontes utilizadas com bastante frequência foi o livro "Sabe aquele gol que o Pelé não fez? Eu fiz! A trajetória esportiva de Duda", da autoria de Suellen Ramos e Silvana Vilodre Goellner, o qual retrata a história de Eduarda Marranghello Luizelli (Duda), ex-atleta e atual coordenadora técnica do departamento de futebol de mulheres do Internacional. A constância dessa referência, ao longo da parte que segue desse artigo, se dá em virtude deste ser o único livro, até o momento, e um dos poucos trabalhos que encontramos que trazem a história do futebol de mulheres no Internacional, embora muito entrelaçado com a trajetória esportiva de Duda.

\section{MULHERES E FUTEBOL NO SPORT CLUB INTERNACIONAL}

O futebol de mulheres no Internacional compõe um capítulo significativo da história das mulheres dentro do futebol no estado do Rio Grande do Sul. Ramos e Goellner (2018) afirmam que a primeira equipe do clube colorado, que se tem registro, foi criada em 1983, tendo como base o time de Porto Alegre, Pepsi Bola. Um ano mais tarde, o clube promoveu a primeira seletiva para formar a equipe adulta. Sobre esse fato, as autoras contam uma curiosidade: não havia categorias de base e muito menos escolinhas de futebol para meninas, motivo pelo qual os times eram formados por mulheres adultas e as mais novas deveriam se encaixar na equipe, caso quisessem jogar futebol. 
As autoras destacam, ainda, que já nesse período o Internacional provinha de uma infraestrutura básica para a equipe, com materiais de treino e jogo, uma comissão técnica com "treinador, preparador físico, preparador de goleiras, tesoureiro, etc." (RAMOS; GOELLNER, 2018, p. 34) e locais de treinamento (o Gigantinho ${ }^{8}$ e o campo suplementar do Beira-Rio ${ }^{9}$ ). No entanto, o clube não viabilizava as viagens para a equipe disputar as competições, ficando a cargo das próprias atletas e familiares custearem estas despesas. De acordo com o site Memória do Inter ${ }^{10}$, "Durante vários anos, no Rio Grande do Sul, não existiram relatos de outra instituição com a estrutura do Inter, apoiando o Futebol Feminino".

Essa assistência gerou frutos e a equipe começou a se sobressair em alguns campeonatos. No ano de 1987, o Internacional conquistava o tricampeonato gaúcho e o terceiro lugar no Campeonato Brasileiro ${ }^{11}$. No entanto, segundo Ramos e Goellner (2018), a partir de 1988, inicia-se um período de escassez de competições para o futebol de mulheres gaúcho, tanto em nível nacional quanto estadual. Por esses fatores, o Internacional optou por extinguir o departamento de futebol de mulheres.

Durante o pequeno período de atividades do departamento, na década de 1980, algumas atletas se destacaram, dentre elas Eduarda Marranghello Luizelli, a Duda. De acordo com Ramos e Goellner (2018), a jovem iniciou jogando futebol nos gramados do clube colorado e compôs a primeira equipe formada em 1984, tendo apenas 13 anos. Segundo as autoras, Duda marcou a trajetória do futebol de mulheres no Internacional enquanto jogadora, com passagens também pelo futebol italiano e pela Seleção Brasileira, mas quando retornou:

[...] da Itália, no segundo semestre de 1995, Duda tinha como objetivo abrir uma escolinha de futebol somente para meninas no Sport Club Internacional. Por já ter participado do elenco de futebol do clube na década de 1980, as portas estavam abertas para a atleta. (p. 60)

Iniciou-se, assim, uma nova era do futebol de mulheres no Internacional, consolidada através da escolinha de futebol da Duda, especificamente para meninas, que funcionava dentro do Internacional, no Parque Gigante ${ }^{12}$. Neste contexto, a parceria

8 O Gigantinho é o ginásio de esportes pertencente ao Sport Club Internacional.

9 O Beira-Rio é o estádio oficial do Sport Club Internacional.

10 Disponível em: <http://memoriadointer.blogspot.com/2016/10/futebol-feminino-pioneirismo-no.html>. Acesso em: 16 de outubro de 2018.

11 Disponível em: <http://memoriadointer.blogspot.com/2016/10/futebol-feminino-pioneirismo-no.html>. Acesso em: 16 de outubro de 2018.

$12 \mathrm{O}$ Parque Gigante é uma área pertencente ao Sport Club Internacional destinada à recreação e lazer dos sócios. Além disso, comporta um Centro de Treinamentos (CT) com estrutura padrão FIFA, que desde 2012 é utilizado pela equipe principal de futebol de homens do clube colorado. 
da franquia de Escolas da Duda com o Internacional não acarretaria em custos ao clube, já que a ligação se daria por intermédio do Centro de Ensino e Treinamento do Internacional e, diante dessa condição, a diretoria aceitou a proposta.

Duda lutava por espaço nas dependências do Internacional. Conquistou sua primeira vitória no dia 07 de setembro 1996, quando a equipe de futebol de mulheres fez seu primeiro treino oficial no campo suplementar do estádio Beira-Rio. Elas fariam um jogo preliminar do Campeonato Brasileiro de homens. Seu engajamento em prol do futebol de mulheres começava a dar resultados. A partir dali, consolidava-se a modalidade dentro do clube colorado, e Duda se tornava referência não só dentro do campo, mas fora dele também. (RAMOS; GOELLNER, 2018, p. 64)

De acordo com o site Memória do Inter $^{13}$, com a retomada do futebol de mulheres, a partir da iniciativa de Duda, o Internacional viu a modalidade deslanchar, consagrando-se campeã em várias competições, seja em campo ou em quadra, já que, no futsal, as atletas também demonstravam sua força e participação. Além disso, o clube colorado foi responsável por ceder várias atletas à seleção brasileira ao longo de sua história. Bel, Sônia, Maria, Priscilla, Solange, Rosana e Karina, além de Duda foram algumas das jogadoras que vestiram a camisa verde e a amarela, representando o clube colorado.

No entanto, a alegria durou pouco. No ano de 2001, o departamento de futebol de mulheres do Internacional começou a passar por dificuldades, principalmente de cunho financeiro. Em janeiro do mesmo ano, o Jornal Correio do Povo anunciava os riscos do departamento ser encerrado por falta de patrocínio, já que "Esse parece ser um dos obstáculos enfrentados pelo futebol de mulheres dentro dos clubes de camisa: a troca de direção. A inconstância de investimentos é algo que permeia o futebol de mulheres" (RAMOS; GOELLNER, 2018, p. 78).

Embora com as ameaças de fechamento, o departamento resistiu até o ano de 2004, quando teve de encerrar suas atividades. Para Ramos e Goellner (2018),

Três fatores apareceram como determinantes para o encerramento das atividades: o acúmulo de ações trabalhistas de jogadoras contra o clube, o fim do incentivo à modalidade com a troca da diretoria e a mudança do modelo do clube em seu projeto de escolinhas, que entrava em conflito com o que Duda desenvolvia no Parque Gigante. (p. 93)

Tatiele, então treinadora da equipe de futebol de mulheres do Internacional e ex-atleta do clube, em nossa conversa, apontou outro motivo que levou ao fechamento do departamento de futebol de mulheres em 2004: a falta de competições no nível nacional,

13 Disponível em: <http://memoriadointer.blogspot.com/2016/10/futebol-feminino-pioneirismo-no.html>. Acesso em: 16 de outubro de 2018. 
enfraquecendo o argumento que sustentava a manutenção da equipe, uma vez que as competições foram se tornando escassas, até não serem mais realizadas. Tal indicação corroborou com o que, em outra ocasião, Duda também destacou: "Não lembro de termos jogado naquela época algum campeonato de maior expressão. Praticamente não existiam escolinhas femininas para jogarmos contra” (RAMOS; GOELLNER, 2018, p. 92).

Para Ramos $(2017)^{14}$, o futebol de mulheres tem como características interrupções e descontinuidades. No estado do Rio Grande do Sul, de 2004 a 2008 foram quatro anos de lacuna de campeonato estadual, o qual não foi desenvolvido por nenhuma entidade. A autora reafirma que, além de não existirem competições, os departamentos de futebol de mulheres do Internacional e do Grêmio, principais clubes do estado, encerraram suas atividades nesse período.

No ano de 2007, após 3 anos sem atividades vinculadas ao futebol de mulheres, o Internacional estabelece nova parceria com a Escola da Duda para disputar a Copa do Brasil Feminina. De acordo com uma notícia ${ }^{15}$ vinculada ao site do Internacional, em outubro de 2007, a Confederação Brasileira de Futebol (CBF) convidou a equipe colorada para participar da primeira edição da competição, em função de ser uma das melhores colocadas no ranking nacional. Sem equipe de futebol de mulheres, o Internacional recorreu à Duda para, mais uma vez, acertar uma parceria com a escolinha de futebol, que já participava de competições na modalidade.

Ainda na reportagem, o diretor da época, Bernardo Stein, explica: "Vamos reativar o departamento, a princípio, para participar da Copa do Brasil. A Duda está trazendo suas jogadoras e comissão técnica e nós vamos disponibilizar toda a nossa estrutura, como campo de treino, fardamento, equipe médica, fisioterapia e logística”. Como previsto, a parceria se encerrou ao final da competição. Tatiele, durante a conversa, atribui o convite da CBF para participar da Copa do Brasil à referência que era a equipe de mulheres do antigo departamento, principalmente no início dos anos 2000, quando os resquícios do sucesso não tiraram por completo o Internacional do cenário nacional.

No ano de 2016, Duda obtém uma nova conquista para o futebol de mulheres colorado, que se transformaria, mais tarde, em uma nova fase para o futebol de mulheres do Internacional. Após alguns anos insistindo, em 2016 a diretoria aceita a proposta

14 Disponível em: <https://www.ludopedio.com.br/arquibancada/gurias-da-bola/>. Acesso em: 17 de outubro de 2018.

15 Disponível em: $\langle$ http://www.internacional.com.br/conteudo?modulo=2\&setor=18\&codigo=5850>. Acesso em: 17 de outubro de 2018. 
da escolinha da Duda funcionar dentro do Parque Gigante. Para Tatiele, essa conquista refletiu no primeiro passo para o retorno no futebol de mulheres ao clube, conforme sua fala: "Eu acho que [foi] o primeiro contato que a Duda retornou o futebol feminino dentro do clube, através dessa parceria com o espaço. Então nós tínhamos a escola feminina da Duda dentro do espaço, estrutura do Inter que era o Parque Gigante". (Conversa com Tatiele, 15/08/2018). A então treinadora ainda menciona uma curiosidade "[...] a gente mandou fazer o uniforme da escolinha vermelho, aí tinha o símbolo do Inter de um lado e o logo da Duda no outro, levava dois escudos a Escola". (Conversa com Tatiele, 15/08/2018).

Ao relatar este fato, Tatiele também comenta sobre a relação entre o Profut ${ }^{16}$ e a sinalização do Internacional favorável ao futebol de mulheres no clube, por meio dessa parceria com escolinha da Duda. O Profut, em seu Art. $4^{\circ}$ apresenta as condições exigidas para que as entidades desportivas se mantenham, dentre as quais se destaca no inciso $\mathrm{X}$ : "manutenção de investimento mínimo na formação de atletas e no futebol feminino e oferta de ingressos a preços populares, mediante a utilização dos recursos provenientes". Essa relação, sinalizada por Tatiele, nos convida a pensar que: se os clubes deveriam, a partir da Lei do Profut, manter um investimento mínimo no futebol "feminino", sem que haja uma especificidade na própria lei do que seria esse investimento no que se refere ao valor investido, à estrutura provida, entre outros tipos de investimentos necessários para que o futebol de mulheres se desenvolva, isso não torna a legislação vaga nesse quesito? Essas condições, por exemplo, respaldam a parceria entre o Internacional e a Escola da Duda, no que tange ao funcionamento da escolinha dentro do Parque Gigante, como um investimento mínimo, ou seja, o Internacional estaria adequado a essa legislação vigente, mesmo provendo apenas o espaço.

Apesar disso, no mesmo ano em que a Escola da Duda se estabeleceu no Parque Gigante, ocorreu a divulgação do novo Regulamento de Licenças da CONMEBOL contendo algumas modificações, entre as quais destaca-se a obrigatoriedade de manutenção de uma equipe de futebol de mulheres, vinculada aos clubes de futebol de homens. Podemos dizer que sim, foi um "gol de placa" da Duda, já que se constituiu em um cenário perfeito para o princípio de um desenvolvimento adequado do futebol de mulheres dentro do Internacional. Duda, que já era uma referência para o clube enquanto jogadora, com a escolinha presente mais uma vez no Parque Gigante, também se tornou uma referência enquanto gestora.

\footnotetext{
${ }^{16}$ Programa de Modernização da Gestão e de Responsabilidade Fiscal do Futebol Brasileiro, sancionado por meio da Lei $\mathrm{n}^{\mathrm{o}} 13.155$, de 4 de agosto de 2015, que tem como objetivo ajudar as entidades desportivas profissionais de futebol a quitarem suas dívidas com a União
} 
Segundo Tatiele, após a divulgação do novo regulamento da CONMEBOL, a diretoria do Internacional estabeleceu um primeiro contato com a Duda, com o intuito de retomar o futebol de mulheres no Internacional, a partir da reativação do seu departamento, já que, nesse momento, só a parceria com o espaço não bastava. Assim, em fevereiro de 2017, o clube anunciou, oficialmente, o retorno do futebol de mulheres, tendo Duda como coordenadora técnica e Cézar Schunemann como diretor de futebol "feminino", sob a gestão do presidente Marcelo Medeiros. Todavia, o departamento ficou vinculado à vice-presidência de relacionamento social e não à vice-presidência de futebol, instância de onde parte os maiores investimentos para o futebol.

Considerando este feito como uma vitória fora de campo, Ramos e Goellner (2018) ressaltam que o clube reativou o seu departamento com o objetivo de se tornar uma das potências dentro do futebol de mulheres do estado e do Brasil. Na reportagem do site do Internacional, que anuncia a retomada da equipe de mulheres ${ }^{17}$, alguns objetivos para os próximos anos são colocados: “a formação de equipes em condições de buscar o título estadual em todas as categorias; a consolidação da estrutura do departamento; a busca de parceiros comerciais; e a participação no campeonato nacional em 2018”.

Seguido do anúncio do retorno do futebol de mulheres no Internacional, iniciou-se um intenso trabalho para montar o time. Segundo o relato de Tatiele, a Escola da Duda já possuía uma equipe adulta, a qual era a atual campeã do Campeonato Gaúcho. Contudo, a Seleção Gaúcha convocou muitas das atletas, as quais deixaram o vínculo com a Duda para fazer parte da seleção, que havia estabelecido uma parceria com o Grêmio Foot-Ball Porto Alegrense para disputar o Campeonato Brasileiro A1. Dessa forma, a equipe adulta da escolinha da Duda estava com poucas atletas, que não eram tecnicamente as melhores. Assim, o clube sentiu a necessidade de realizar uma "peneira", ou seja, uma avaliação técnica.

Considerada a segunda maior peneira da história do futebol de mulheres, recebeu mais de 700 meninas e mulheres no Centro de Treinamento Morada dos Quero-Queros, em Alvorada. Elas foram avaliadas entre as categorias sub-13, sub-15, sub-17 e adulta. (RAMOS; GOELLNER, 2018, p. 108)

Vale salientar que as atletas vieram de vários estados do país em busca de um clube que lhe abrisse as portas e oportunizasse realizar o sonho de jogar futebol. Para tanto, Suellen, preparadora física da equipe, atribui o sucesso da "peneira" à carência de espaços para as mulheres jogarem futebol:

17 Disponível em: <http://www.internacional.com.br/conteudo?modulo=2\&setor=18\&codigo=37508>. Acesso em: 06 de outubro de 2018. 
Em fevereiro, se não me engano, não me lembro muito bem, aconteceu a peneira, que é uma das maiores peneiras do Brasil, que reuniu em média 700 atletas querendo fazer parte do clube. Pra tu vê né, como a modalidade carecia desse retorno, não só do Inter, mas como tem muita mulher que joga futebol e não tem onde jogar. Então, foi isso o que nos refletiu, assim, essa peneira". (Conversa com Suellen, 18/06/2018)

Tais investimentos voltaram a dar retorno ao clube. Nas categorias de base, Ramos e Goellner (2018) comentam sobre as conquistas no sub-15 e no sub-17, que ainda em 2017, tiveram a oportunidade de disputar o Campeonato Gaúcho. Na categoria sub-15 o Internacional ficou com o vice-campeonato e, na categoria sub-17, sagrou-se campeão. Enquanto isso, a equipe adulta tinha como principal objetivo o Campeonato Gaúcho para retornar ao cenário nacional, em 2018. Com uma campanha arrebatadora, a equipe foi para a final com $100 \%$ de aproveitamento, tendo como adversário a equipe do Grêmio Foot-Ball Porto Alegrense, de modo que a final do campeonato seria nada menos que um Gre-Nal, o maior clássico gaúcho.

Novamente o trabalho do grupo rendeu frutos, sendo o principal deles disputar a final do Campeonato Gaúcho dentro do Beira Rio, ao lado da torcida colorada. Tatiele ressalta que o clube abriu as portas para a equipe de mulheres, devido ao trabalho desenvolvido ao longo do ano, que, na reta final, resultou num maior apoio à equipe, principalmente em termos de investimento. Diante desse cenário, esta sagrou-se campeã gaúcha de 2017, garantido a oportunidade de disputar a seletiva do Campeonato Brasileiro A2, em 2018.

A retomada do futebol feminino trouxe resultados meteóricos a curto prazo. O projeto foi elaborado para colocar o clube gaúcho no topo da elite nacional em três anos, com o objetivo de participar de competições nacionais. Será mais uma equipe de camisa lutando por espaço. (RAMOS; GOELLNER, 2018, p. 112)

Em 2018, a equipe se classificou na seletiva do Campeonato Brasileiro A2, contudo, foi eliminada na semifinal da competição. De qualquer forma, tal resultado não abalou o grupo num primeiro momento, nem mesmo seu departamento, que no segundo semestre de 2018 disputou o Campeonato Gaúcho almejando o bicampeonato, que também não veio. Por ter se classificado entre as quatro melhores equipes no Campeonato Brasileiro A2, as Gurias Coloradas, como carinhosamente ficou conhecida a equipe, ascenderam para a Série $\mathrm{A} 1^{18}$.

Portanto, a história do futebol de mulheres no Sport Club Internacional é muito rica, principalmente no que se refere às conquistas nos gramados e fora dele. $\mathrm{O}$ bom desempenho é apenas reflexo do investimento e da responsabilidade da diretoria do clube

18 Salientamos que, em 2019, a então treinadora da equipe, Tatiele, não teve o contrato renovado com o clube. 
com a modalidade. Até o momento, percebemos que há um incentivo promissor para o futebol de mulheres no Internacional, mas ressaltamos que ainda há muito o que se fazer.

\section{CONSIDERAÇÕES FINAIS}

Partimos de uma pesquisa que visou diagnosticar a relação entre mulheres e futebol no Rio Grande do Sul e, no caso deste artigo, no Sport Club Internacional. A partir de alguns questionamentos, surgiu esta investigação. Estes nos forçaram a tomar decisões de método para tentar respondê-los e permitiram que construíssemos o quadro aqui apresentado. Além disso, o objetivo de acompanhar e descrever como se deu e se dá esta implicação, de modo localizado, em um clube de futebol profissional, nos ajudou a complexificar algumas explicações que nos pareciam ter fácil acolhimento e que estão ao lado de relegar as mulheres a um plano menos visível e menos importante.

Em síntese, podemos destacar que os resultados alcançados, diferentemente daqueles que fazem atribuições unicausais, apontam para um conjunto de acontecimentos que passam pela aproximação das mulheres ao clube desde o princípio, a história de conquistas do antigo departamento de futebol de mulheres, as legislações e a necessidade de adequação do clube para poder disputar competições importantes do futebol de homens, em conjunto com pessoas determinadas a desenvolver o futebol de mulheres e uma diretoria que se propõe a abrir as portas para a modalidade. Dessa maneira, o que encontramos foi uma rede de acontecimentos nos quais as mulheres protagonizam, em diferentes oportunidades, disputas por espaços que não nos permitem acatar qualquer explicação unicausal ou na qual as próprias mulheres não assumam protagonismo.

\section{REFERÊNCIAS}

BRASIL. Lei ${ }^{\circ} 13.155$, de 4 de agosto de 2015. Diário Oficial da República Federativa do Brasil, Brasília, 05 de ago. 2015, p. 1.

CERTEAU, Michel de. A invenção do cotidiano: 1, Artes de fazer. 22. ed. Petrópolis: Vozes, 2003. CONMEBOL, Confederación Sudamericana de Fútbol. Reglamento de Licencias de Clubes de la CONMEBOL. 2016.

GONÇALVES, Vanessa Bugs. Táticas e estratégias: uma desconstrução da noção de indisciplina no cotidiano escolar. 2018. 151 f. Tese (Doutorado) - Faculdade de Educação, Universidade Federal de Pelotas, Pelotas, 2018. 
MOREL, Marcia; SALLES, José Geraldo do Carmo. Futebol Feminino. In: COSTA, L. (Org.). Atlas do esporte no Brasil. Rio de Janeiro. 2006. p. 8.264-8.265.

RAMOS, Suellen dos Santos; GOELLNER, Silvana Vilodre. Sabe aquele gol que o Pelé não fez? Eu fiz! A trajetória esportiva de Duda. Rio de Janeiro: Drible de Letra, 2018.

RAMOS, Suellen dos Santos. Gurias da Bola: futebol e mulheres no Rio Grande do Sul. Ludopédio. 2017. Disponível em: <https://www.ludopedio.com.br/arquibancada/gurias-da-bola/>. Acesso em: 17 de outubro de 2018. 